Fixed Point Theory, 22(2021), No. 1, 189-204

DOI: $10.24193 /$ fpt-ro.2021.1.13

http://www.math.ubbcluj.ro/ ${ }_{\text {nodeacj/sfptcj.html }}$

\title{
POSITIVE SOLUTIONS FOR A FRACTIONAL BOUNDARY VALUE PROBLEM VIA A MIXED MONOTONE OPERATOR
}

\author{
J. HARJANI*, B. LÓPEZ** AND K. SADARANGANI*** \\ *Departamento de Matemáticas, Universidad de Las Palmas de Gran Canaria, \\ Campus de Tafira Baja, 35017 Las Palmas de Gran Canaria, Spain \\ E-mail: jackie.harjani@ulpgc.es \\ ** Departamento de Matemáticas, Universidad de Las Palmas de Gran Canaria, \\ Campus de Tafira Baja, 35017 Las Palmas de Gran Canaria, Spain \\ E-mail: belen.lopez@ulpgc.es \\ *** Departamento de Matemáticas, Universidad de Las Palmas de Gran Canaria, \\ Campus de Tafira Baja, 35017 Las Palmas de Gran Canaria, Spain \\ E-mail: kishin.sadarangani@ulpgc.es
}

Abstract. In this paper, by using a mixed monotone operator method we study the existence and uniqueness of positive solutions to the following nonlinear fractional boundary value problem

$$
\left\{\begin{array}{l}
{ }^{C} D_{0^{+}}^{\alpha} u(t)+f(t, u(t),(H u)(t))+g(t, u(t))=0, \quad 0<t<1, \\
u(0)=u^{\prime \prime}(0)=0, \quad u^{\prime}(1)=\gamma u^{\prime}(\eta),
\end{array}\right.
$$

where $2<\alpha \leq 3, \gamma, \eta \in(0,1),{ }^{C} D_{0^{+}}^{\alpha}$ denotes de Caputo fractional derivative, $f:[0,1] \times[0, \infty) \times$ $[0, \infty) \rightarrow[0, \infty)$ and $g:[0,1] \times[0, \infty) \rightarrow[0, \infty)$ are continuous functions and $H$ is an operator (not necessarily linear) applying $\mathcal{C}[0,1]$ into itself. Moreover, in order to illustrate our results, we present some examples.

Key Words and Phrases: Fractional boundary value problem, positive solution, mixed monotone operator, fixed point.

2020 Mathematics Subject Classification: 47H10, 49L20.

Acknowledgements. The first and the third authors were partially supported by the project PID2019-106093GB-I00.

\section{REFERENCES}

[1] H. Afshari, H. Marasi, H. Aydi, Existence and uniqueness of positive solutions for boundary value problems of fractional differential equations, Filomat, 31(2017), 2675-2682.

[2] J. Caballero, B. López, K. Sadarangani, On monotonic solutions of an integral equation of Volterra type with supremum, J. Math. Anal. Appl., 305(2005), 304-315.

[3] J.R. Graef, L. Kong, Q. Kong, Application of the mixed monotone operator method to fractional boundary value problems, Fract. Diff. Cal., 2(2012), 87-98.

[4] M. Jleli, B. Samet, Existence of positive solutions to an arbitrary order fractional differential equation via a mixed monotone operator method, Nonlinear Analysis: Modelling and Control, $\mathbf{2 0}(2015), 367-376$. 
[5] A.A. Kilbas, H.M. Srivastava, J.J. Trujillo, Theory and Applications of Fractional Differential Equations, North-Holland Mathematics Studies, 204, Elsevier Science B.V., Amsterdam, 2006.

[6] V. Lakshmikantham, S. Leela, J. Vasundhara Devi, Theory of Fractional Dynamic Systems, Cambridge Academic Publishers, Cambridge, 2009.

[7] K.S. Miller, B. Ross, An Introduction to the Fractional Calculus and Fractional Differential Equations, John Wiley and Sons, New York, 1993.

[8] I. Podlubny, Fractional Differential Equations, Academic Press, San Diego, 1999.

[9] J. Sabatier, D.P. Agrawal, J.A.T. Machado, Advances in Fractional Calculus: Theoretical Developments and Applications in Physics and Engineering, Springer, Dordrecht, 2007.

[10] S.G. Samko, A.A. Kilbas, O.I. Marichev, Fractional Integrals and Derivatives, Theory and Applications, Gordon and Breach, Yverdon, 1993.

[11] F.J. Torres, Existence of positive solutions for a boundary value problem of a nonlinear fractional differential equation, Bull. Iranian Math. Soc., 39(2013), 307-323.

[12] C. Zhai, M. Hao, Fixed point theorems for mixed monotone operators with perturbation and applications to fractional differential equation boundary value problems, Nonlinear Anal., 75(2012), 2542-2551.

[13] C. Zhai, M. Hao, Mixed monotone operator methods for the existence and uniqueness of positive solutions to Riemann-Liouville fractional differential equations boundary value problems, Boundary Value Problems, 2013(2013), 2013:85.

[14] J. Zhang, C. Yang, C. Zhai, A mixed monotone operator method for the existence and uniqueness of positive solutions to impulsive Caputo fractional differential equations, Discrete Dyn. Nature and Society, vol. 2013, art. ID745674, 8 pages.

Received: January 17, 2019; Accepted: January 7, 2020. 
